\title{
Rhithrogena grischuna nov. sp., a new mayfly species from eas- tern Switzerland related to $R h$. hercynia Landa, 1969 (Ephemeroptera ; Heptageniidae)
}

\author{
M. Sartoril \\ R. Oswald ${ }^{2}$
}

Keywords : Ephemeroptera. new species, Rhithrogena, Heptageniidae, Switzerland.

A new species, Rhithrogena grischuma nov. sp., is deseribed at all stages (imagines, subimagines, nymphs and eggs) from material collected in eastem Switzerland. This species belongs to the hybrida group, and is related to Rh. hercynia and allied species, for which we propose a new group, the hercynia group, characterized by the presence of dark spots on the upper face of the femora, both in imaginal and larval stages.

Some ecological and biocoenotic data on $R h$. grischuna are also given.

Rhithrogena grischuna nov. sp., une nouvelle espèce d'éphémère de Suisse orientale apparentée à Rh. hercynia Landa, 1969 (Ephemeroptera, Heptagenirdae)

Mots clés : Ephemeroptera, espèce nouvelle, Rhithrogena, Heptageniidae, Suisse.

Une nouvelle espèce, Rhithrogena grischtuna nov sp., est décrite à tous les stades (imagos, subimagos, larves et oeufs) à partir de matériel récolté en Suisse orientale. Cette espèce appartient au groupe hybrida, et est étroitement apparentée à $R h$. hercynia et autres especces affines, pour lesquelles nous proposons un nouveau groupe, le groupe hercynia. caractérisé par la présence de taches foncées sur la face supérieure des fémurs, tant aux stades larvaire qu'imaginal.

Quelques données écologiques et biocénotiques sur $R h$. grischuna sont également présentées.

\section{Introduction}

In Europe, the genus Rhithrogena is probably the most diversified among the Ephemeroptera. Until now, more than fifty species have been described.

-In a synthetical work devoted to that genus, Sowa (1984) proposed some species groups on the basis of larval and imaginal characters. The new species described here belongs to the so-called hybrida group. The most important patterns of these species are :

1. Musée zoologique, Pl. Riponne 6, C.P. 448, CH-1000 Lausanne 17. Switzerland.

2. Zoologisches Museum, Universität Zürich, Winterthurerrstrasse 190, CH-8057 Zürich, Switzerland.
- In male imagines : forewings often colored ; penis lobes spread out and cylindrical with the outer tooth generally not visible in ventral view; inner tooth smaller and also conspicuous in ventral view too. - In nymphs : lateral sclerites of the first sternite quadratic with their anterior margin perpendicular to the body axis; all gills crenulated.

This group includes today somewhat less than twenty species. Recently Belfiore (1987) proposed a new group for two species, $R h$. nuragica Belfiore and $R h$. insularis Esben-Petersen, the latter one previously considered in the hybrida group. In so far as the dividing of species into groups reflects more their morphological affinities rather than some phylogenetic relationships, we propose a new group, called hercynia group, with the following features: 
- Species previously belonging to the hybrida group that possess a dark spot on the upper face of the femora, both in nymphs and adults.

The hybrida group would be therefore restricted to the species in which the upper face of the femora are without such a dark spot.

Table I itemizes the known species belonging to these groups.

During field work led by the junior author in the eastern part of Switzerland (Canton of Graubünden), important populations of a species related to the hercynia group were found. The rearing of specimens allowed us to establish that they did not belong to an already described species.

Table 1. Systematic position of the species related to the Rh. hybrida group.

\section{hybrida group}

Rh. nivata (Eaton, 1871)

Rh. hybrida Eaton, 1885

Rh. degrangei Sowa, 1969

Rh. strenua Thomas, 1982

Rh. puthzi Sowa, 1984

Rh. reatina Sowa \& Belfiore, 1984

Rh. endenensis Metzler et al., 1985

Rh. sibillina Metzler et al., 1985

Rh. circumtatrica Sowa \& Soldán, 1986

Rh. diensis Sowa \& Degrange, 1987

Rh. fonticola Sowa \& Degrange, 1987

Rh. mariaedominicae Sowa \& Degrange, 1987

\section{insularis group}

Rh. insularis Esben-Petersen, 1913

Rh. nuragica Belfiore, 1987

\section{hercymia group}

Rh. fiorii Grandi, 1953

Rh. hercynia Landa, 1969

Rh. gratianopolitana Sowa et al., 1986

Rh. corcontica Sowa \& Soldán, 1986

Rh. podhalensis Sowa \& Soldán, 1986

Rh. grischuna nov. sp.
2. Description of $R$ hithrogena grischuna nov. sp.

\section{Male imago}

Body length : 10.2-11.0 mm; forewing : 11.7-12.1 $\mathrm{mm}$; cerci : $27.30 \mathrm{~mm}$.

Face of the head olivaceous grey, antennae middle brown. Basis of ocelli dark brown. Eyes large, beige grey dorsally, basal portion silver grey.

Thoracical sclerites dark brown to black brown. Forewing intensively colored brown in the basal half. Veins dark brown, except the Sc and M1 light brown, and the big transversal whitish. Pterostigmatic area milky, with 13-15 transversal veins. Forelegs with femora and tibiae medium brown, tarsi greyish brown. Middle and hing legs olivaceous brown. Femora with a distinct elonga ted violet spot in the middle of the upper face.

Abdominal terga uniformly medium brown, segment borders sometimes paler. Sterna light brown; in the anterior part, two small elongated spots, darker and directed downwards. Nerve ganglia hardly visible, without any kind of coloration.

Cerci dark brown in proximal part, gradually lighter.

Genitalia.

Styliger laterally dark brown, medium brown in the central portion. Posterior margin moderately incurved (Fig. 1).

Penis, in ventral view (Fig. 2), with membraneous part at the base of lobes. Inner margin of penis lobes clearly convex in the distal part, and covered with membraneous folds in the middle. Inner tooth quite visible. In apical view (Fig. 3), penis lobe semiquadratic with genital pore well developed. In parallel median view, see in Fig. 4. In lateral view (Fig. 5), external tooth and apical margin of penis lobe with slightly concave contour. Titillators (Fig, 6) with subparallel margins, bearing 3-5 teeth. Generally, one supplementary tooth visible on their surface.

\section{FEMALE IMAGO}

Body length ; $11.5-12.5 \mathrm{~mm}$; forewing : 12.8-15.0 $\mathrm{mm}$; cerci : $18-22 \mathrm{~mm}$.

Face of the head olivaceous grey, antennae brown, 

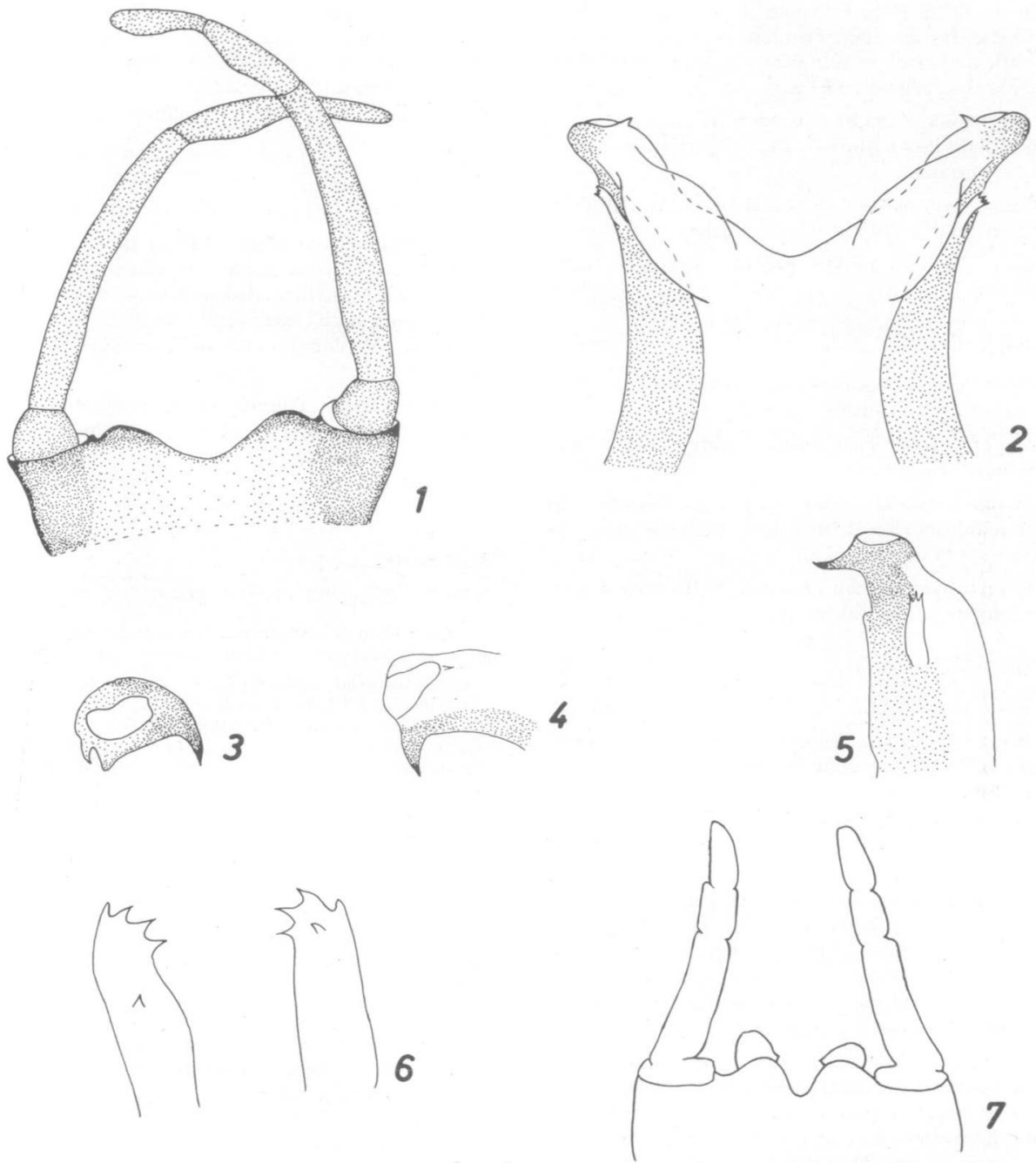

Figs $1-7 ; R h$. grischuna nov. sp. 1-6: male imago: $7:$ male subimago.

Fig. 1 : styliger plate and gonostyles in ventral view; Fig. 2 : penis in ventral view : Fig. 3 : penis lobe (left) in caudal view : Fig. 4 : penis lobe (right) in parallel median view : Fig. $5:$ penis in lateral view; Fig. 6 : titillators ; Fig. $7:$ genitalia in ventral view. 
Thoracical sclerites medium brown. Forewings colorless, veins dark brown. Pterostigmatic area milky as for the male. Forelegs olivaceous brown, middle and hindlegs yellowish brown. Femora of all legs with an elongated spot.

Abdominal terga brown, each of them with two small light spots. Sterna paler, with the same spots as for the male.

Subgenital plate with posterior margin slightly convex, rather subrectilinear, without incision.

Cerci light to middle brown, darker in basal portion:

\section{Male subimago}

Body length : 9.2-10.0 $\mathrm{mm}$; forewing : 11.5-12.0 $\mathrm{mm}$; cerci : $12.13 \mathrm{~mm}$.

General color dark brown, except the thorax medium brown.

Wings brownish grey in basal part, dark grey in the distal one; veins brownish. All legs with elongated spots on femora.

Sterna lighter than terga. Genitalia as in Fig. 7. Styliger plate deeply incised.

\section{NYMPH}

Body length : 11.5-12.5 mm; cerci : $7.3-7.8 \mathrm{~mm}$.

Body dark brown. Femora of all legs with a distinct large violet spot in the middle of the light centra] area (Fig. 8).

Head dark brown, thorax middle brown. Abdominal terga I-IV light brown, gradually darker. Terga V-VI dark brown, VII with inconspicuous lighter lateral areas. Terga VIII-IX with big light spots separated by dark elongated central band. Tergum $X$ dark brown. Sterna lighter than terga, middle brown, without any maculation on nerve ganglia. Same spots as in the imagos also visible. Cerci light brown, darker on the proximal part.

Labrum slightly incurved in the middle of the anterior margin. Middle combs of distal part of the maxilla with 10-13 teeth (Fig. 9). Spines on the upper face of hind femora with distinct divergent margins and truncate apex (Fig. 10). Claws generally with 2 teeth.

All gills moderately crenulated. Lamella of the first gill with well developed semilunar plica
(Fig. 11). Second gill with large lamella and central sclerite rather narrow (Fig. 12). Sixth and seventh pairs of gills as in figs 13 and 14. Central portion of the posterior margin of abdominal tergum V (Fig. 15) with long and pointed teeth, slightly rounded. Submarginal microdenticles numerous.

\section{EGGS}

Length : ca. $160 \mu \mathrm{m}$; width : ca. $100 \mu \mathrm{m}$.

General size ovoid (Fig. 16). Polar cap at one of the poles (Fig. 17), with numerous adhesive elements. Exochorionic surface also with some adhesive elements and with macrogranules very irregulary arranged. Micropyle with well developed margin (Fig. 18).

In comparison, the eggs of $R h$. gratianopolitana are bigger (Fig. 19), the polar cap is more extended (Fig. 20), the macrogranules on the exochorionic surface are less numerous, and the margin of the micropyle is less developed (Fig. 21).

\section{Material examined}

Switzerland, Canton of Graubünden : $1 \sigma$ holotype, 19 allotype, 3 ơ 2 \%, 2 s.i. $\sigma^{\circ}$ (all with nymphal exuviae), as well as 37 nymphs paratypes : Rein Anteriur River (Vorderrhein), Disentis/Muster, 1,050 m a.s.l., 2-5.VI.1988.

Other material : 6 larvae (L), 4.V.1988, 8 L, 20.V.1988, same locality : $3 \mathrm{~L}$, same river, Zignau, $850 \mathrm{~m}, 4 . \mathrm{V} .1988$; $1 \mathrm{~L}$, same river, Castrisch, $720 \mathrm{~m}, 4 . \mathrm{V} .1988$; $1 \mathrm{~L}$, Calanca Valley, Calancasca stream, Auglio, $1,035 \mathrm{~m}, 19 . \mathrm{VI} .1984$ : 2L. same local ity, 18 V. 1985 ; 2L, same stream, Valbella, 1,300 m. 18.V.j985.

Holotype, allotype and paratypes deposited in the Musée zoologique Lausanne, except $1 \sigma, 1 \%, 3 \mathrm{~N}$ paratypes in the Zoologisches Museum Zürich.

Eiymology.

Named after the district where this species has been found (Canton of Graubünden) called Grischuma in rhaetoromanic language.

\section{Affinities}

$R h$. grischuna nov. sp. is closely related to $R h$. corcontica Sowa \& Soldán, 1986. It differs from the latter in imaginal stage in that the posterior margin of the styliger is less incurved, the membraneous folds of the penis are less extended, and the distal part of the penis lobes are less rounded. At larval stage. $R h$. grischuna presents the same abdominal patterns than those of $R h$. corcontica. Nevertheless, it can be distinguished by its darker coloration, by 

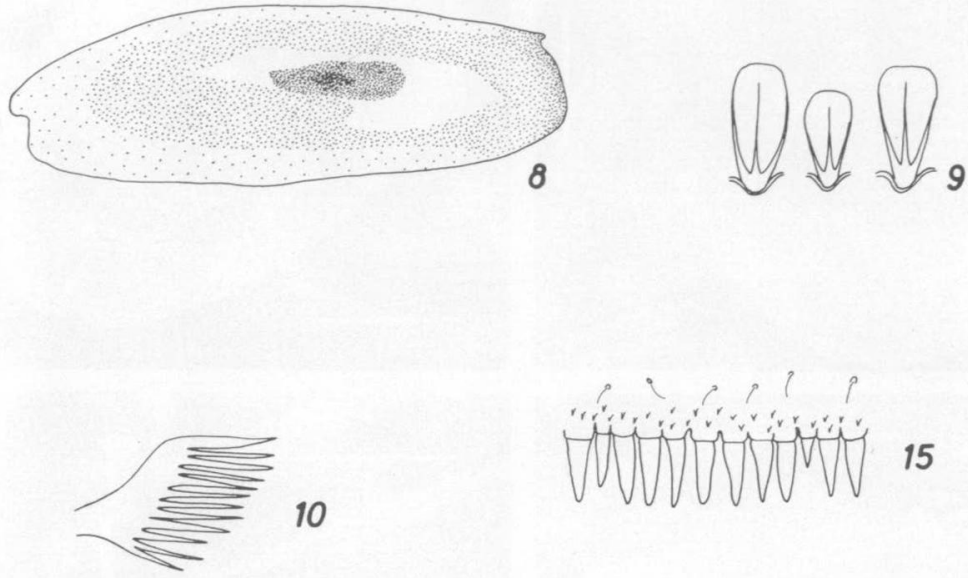

10

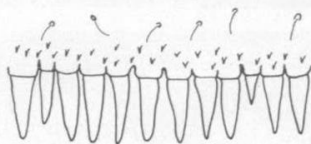

15
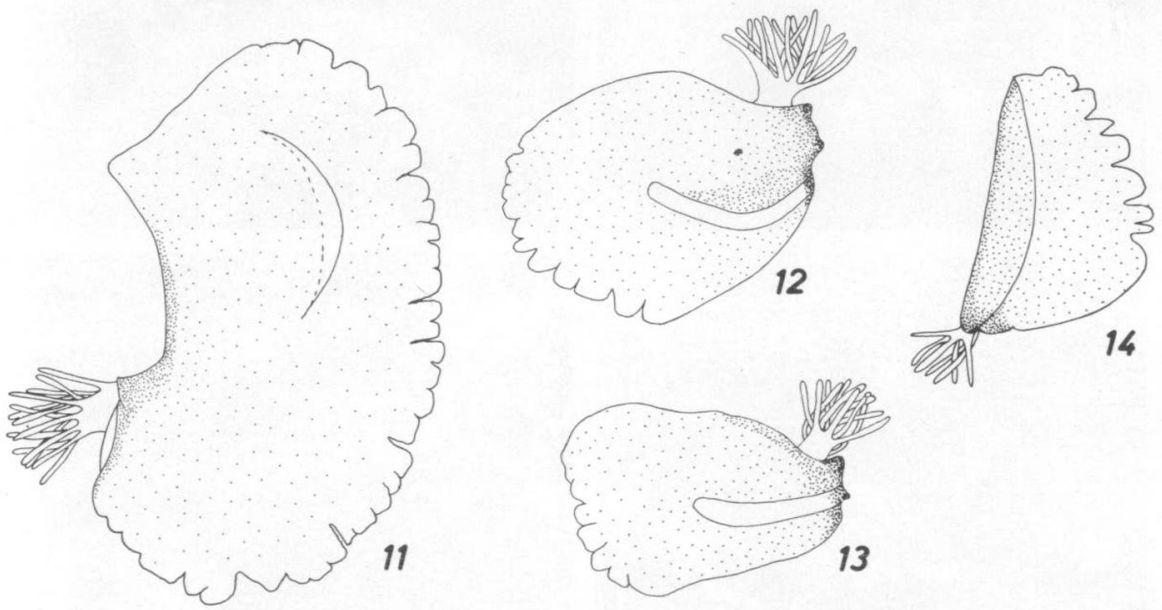

Figs $8.15: R h$. grischuna nov. sp. : nymph.

Fig. 8: upper face of hind femora; Fig. $9:$ spines on the upper face of hind femora; Fig. 10: comb of the distal part of the maxilla ; Fig. 11 : first gill; Fig. 12 : second gill; Fig. 13 : sixth gill; Fig. 14 : seventh gill ; Fig. 15 : posterior margin of the fifth abdominal tergum. 

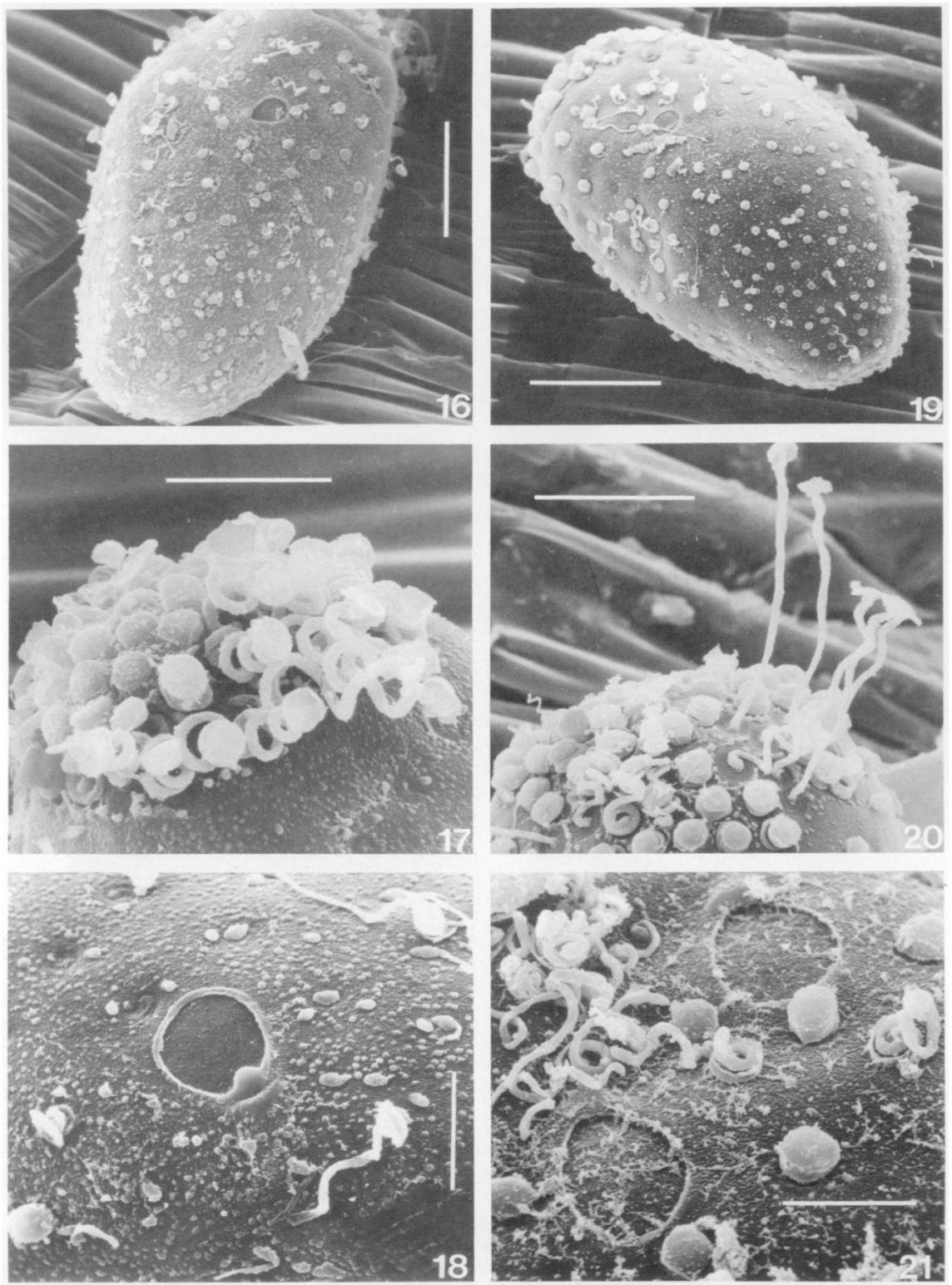

Figs 16-18; Rh. grischuma nov. sp. : egg

Fig. 16 : general view (scale : $40 \mu \mathrm{m}$ ); Fig 17 ; polar cap (scale : $20 \mu \mathrm{m}$ ): Fig. 18 : micropyle and macrogranules (scale : $10 \mu \mathrm{m}$ ); Figs $19.21: R h$. gratianopolitana Sowa, Degrange \& Sartori, $1986:$ egg ; Fig. $19:$ general view (scale : $40 \mu \mathrm{m}$ ); Fig. 20 : polar cap with unrolled adhesive elements (scale : $30 \mu \mathrm{m}$ ) : Fig. $21:$ micropyles and macrogranules (scale : $10 \mu \mathrm{m}$ ). 
Table 2. Physical and chemical compounds of the type locality

\begin{tabular}{|c|c|c|c|c|c|c|c|c|c|}
\hline \multicolumn{4}{|c|}{ PHYSICAL COMPOUNDS } & \multicolumn{6}{|c|}{ GEOCHEMICAL COMPOUNDS } \\
\hline JULY 1987-1988 & mean & $\min$. & $\max$. & $\mathbf{N}$ & ditto [MMOL/M3] & mean & $\min$. & $\max$. & $\mathbf{N}$ \\
\hline $\mathrm{pH}$ & 7.8 & 7.5 & 8.3 & 144 & calcium & 314 & 393 & 214 & 12 \\
\hline conductivity $(\mu \mathrm{S} / \mathrm{cm})$ & 77 & 67 & 85 & 144 & potassium & 48.5 & 41.5 & 57.5 & 12 \\
\hline temperature $\left({ }^{\circ} \mathrm{C}\right)$ & 9.3 & 6.8 & 13 & 144 & magnesium & 47.5 & 38 & 77 & 12 \\
\hline water-level (m) & 0.4 & 0.39 & 0.4 & 144 & sodium & 60 & 52 & 82.5 & 12 \\
\hline discharge $(\mathrm{m} 3 / \mathrm{s})$ & 1.2 & 1.1 & 1.4 & 12 & sulphate & 88.5 & 76 & 104 & 12 \\
\hline pressure (mb) & 893 & 890 & 895 & 144 & chloride & 35 & 22.5 & 65 & 12 \\
\hline porosity & 0.2 & 0.16 & 0.2 & 12 & alkaline earths & 361 & 316 & 470 & 12 \\
\hline \multicolumn{10}{|c|}{ CHEMICAL COMPOUNDS } \\
\hline ditto [MMOL/M3] & \multicolumn{2}{|c|}{ meanmin. } & $\max$. & $\mathbf{N}$ & ditto [MMOLM3] & \multicolumn{2}{|c|}{ meanmin. } & $\max$ & $\mathbf{N}$ \\
\hline total carbon & 778 & 678 & 873 & 12 & total nitrogen & 37 & 29 & 56 & 12 \\
\hline total inorg. $\mathbf{c}$ & 676 & 589 & 794 & 12 & particulate $\mathbf{n}$. & 5.5 & 2.5 & 8.5 & 12 \\
\hline carbon dioxide & 17 & 14 & 22 & 12 & dissolved $\mathbf{n}$. & 31.5 & 26 & 48.5 & 12 \\
\hline bicarbonate & 666 & 573 & 772 & 12 & diss. org. bound $\mathrm{n}$. & $\mathbf{3}$ & 1.5 & 5 & 12 \\
\hline total org. c. & 102 & 79 & 157 & 12 & nitrate & 27.5 & 22.5 & 45 & 12 \\
\hline particulate o.c. & 40 & 28 & 92 & 12 & nitrite & 0.1 & 0.1 & 0.1 & 12 \\
\hline dissolved o.c. & 63 & 49 & 104 & 12 & ammonia & 1.2 & 0.4 & 1.9 & 12 \\
\hline total phosphate & 0.5 & 0.4 & 1.7 & 12 & oxygen theoret. & 317 & 289 & 336 & 12 \\
\hline particulate ph. & 0.2 & 0.1 & 0.3 & 12 & oxygen concent. & 347 & 312 & 369 & 12 \\
\hline dissolved ph. & 0.5 & 0.2 & 1.5 & 12 & o. saturation & 29 & 23 & 33 & 12 \\
\hline ortho-phosphate & 0.5 & 0.2 & 1.5 & 12 & o. over sat (\%) & 9 & 8 & 10 & 12 \\
\hline
\end{tabular}

the size of the spot on the upper face of femora (smaller in $R h$. corcontica), by the presence of numerous submarginal microdenticles on the posterior margin of the terga, and finally, by the shape of the spines on the upper face of hind femora (rounded in $R h$. corcontica).

Rh. grischuna is easily recognizable from $R h$. hercynia, $R h$. podhalensis and $R h$. gratianopolitana mainly by the shape of the penis lobe (especially in caudal view), by the shape of the combs of the lacinia and by the patterns of abdominal terga of the nymphs.

The eggs of $R h$. grischuna, as previously seen, differ from those of $R h$. gratianopolitana, and can also be distinguished from those of $R h$. corconvica and $R h_{l}$. hercynia, especially by the shape of macrogranules on the exochorion, and from those of $R h$. podhalensis by the size of the polar cap (see Figs 32-34 in Sowa \& Soldán 1986).

\section{Distribution and biology}

$R h$. grischuna has been collected in big streams or small rivers, mainly between 800 and $1300 \mathrm{~m}$ above sea level, and seems to belong to metarhithral associations. The physical and chemical compounds of the type locality are summarized in table 2. This species flies from the end of May to the middle of June in the type locality. It has been found together with $R h$. degranget Sowa and $R h$, puthzi Sowa that possess the same flying period, although $R h$. degrangei is a little earlier. These three species are replaced later by $R h$. alpesiris Eaton and $R h$. loyolaea Navàs that fly in August-September. The global mayfly composition is given in table 3 .

The young larvae of $R h$. grischuna are present in the river from the end of summer (September), and, as in the case for all the species of the $R h$. hercynia group, belong to the monovoltine winter species group (Uws) (Clifford 1982). 
Table 3. Mavfly composition of the tvpe localits

\begin{tabular}{|c|}
\hline EPHEMEROPTERA \\
\hline Baetidae \\
Baetis alpinus (Pictet) \\
Baetis rhodani (Pictet) \\
Heptageniidae \\
Epeorus alpicola Eaton \\
Ecdyonurus picteti Meyer-Dür \\
Ecdyonurus venosus (Fab.) \\
Rhithrogena alpestris Eaton \\
Rhithrogena degrangei Sowa \\
Rhithrogena loyolaea Navàs \\
Rhithrogena puthzi Sowa \\
Rhithrogena semicolorata group \\
Rhithrogena grischuna nov. sp. \\
\hline
\end{tabular}

In Switzerland, $R h$. grischuna seems to be vicariant with $R h$. gratianopolitana. The lat ter colonized rather bigger rivers at lower altitudes (200-900 m) (Sowa et al. 1986), and can be considered as a meta-to hyporhithral inhabitant (occasionally epipotamal) (Degrange \& Sowa 1987). Until now, Rh. gratianopolitana has been found only in the western and central part of Switzerland.

The records of $R h$. hercynia in Switzerland (Zurwerra \& Tomka 1984) as well as the re-description of this species on the basis of Swiss material (Metzler et al. 1985) are probably erroneous. The specimens re-described by Sowa \& Soldan (1986) from the type locality are rather different in imaginal, nymphal as well as egg stages. Rh. hercynia sensu Metzler et al. is probably synonym with $R h$. gratianopolitana.

\section{Aknowledgements}

Our sincere thanks are due to Prof. R. Sowa (Krakow) for the kind gift of comparative material of $R h$. corcontica, $R h$. podhalensis and $R h$. hercynia. We are grateful to the staff of the Electronic Microscope Center of the University of Lausanne for their help and advices, especially Dr. Viviane Boutinard-Rouelle and Francine Flach-Biggiogera.

The senior author wishes to thank the Société Vaudoise des Sciences Naturel les (Agassiz.Fonel Funds) for its financial help.

Rejerences

Bet fiore (C.) 1983. Notes on italian Heptageniidae (Ephemeroptera), Rhithrogena fiorit Grandi, 1953 and R. adrianae sp.n. Aquatic Insects $5(2): 69.76$.

Belfiore (C.) 1987. Heptageniidate from Corsica and Sardinia. Rhithrogena nuragica n.sp. R. eatoni Esben-Petersen 1912, and $R$ insularis Esber-Petersen 1913 (Ephemeroptera). Annls Limuol., $23(2) ; 87-94$

Clifford (H.C.) 1982. Life cycles of mayflies, with special reference to voltinism. Quest. Emt., $18(\mathrm{t}-4): 15-90$.

Degrange (Ch) \& Sowva (R.) 1987. Ephéméroptè res et Plécoptères témoins de la dégradation et de la restauration d'une rivière: I'Isère dans sa traversée de l'agg lomération grenobloise. Actes 112 Congrès national des Sociétés savanies, Lyon 1987, Sciences, fasc. III : 141-152.

Metzler (M.). Tomka (I.) \& Zurwerra (A.) 1985. Beitrag zur Kenntnis der europäischen $R$ hit hrogena.Arten : nivata, hybrida und hercynia, sowie Beschreibung von zwei neuen Arten. Folia Ent. Hung. 46(2): $117-135$

Sowa (R.) 1984. Contribution à la connaissance des espèces européennes de Rhithrogena Eaton (Ephemeroptera. Heptageniidac) avo le rapport particulier aux especes des Alpes et des Carpates. Proc. IV'h Intern. Confer. Ephemeroptera. V. Landa et al. eds : $37-52$.

Sowa (R.), Degrange (Ch.) \& Sartori (M.) 1986. Rhithrogena gratianopolitana sp. n. du groupe hybrida (Ephemeroptera, Heptageniidae) des Alpes françaises et helvétiques. Bull. Soc. Vaud. Sc. Nat., $78(2): 215-223$.

Sowa (R.) \& Soldán (T.) 1986. Three new species of the Rhithrogena hybrida group from Poland and Tchechoslovakia, with a supplementary description of $R h$. hercynia Landa, 1969 (Epheme roptera, Heptagenildae). Pol, Pismo Entomol., 56 : 557-572.

Zurwerra (A.) \& Tomka (I.) 1984. Beitrag zur Kenntnis der Eintagsfliegenfauna der Schweiz (Insecta, Ephemeropiera). Bull. Soc: Frib. Sc. Nat. 73(1/2) : $139-146$. 